\title{
AN INNOVATION IN THE TEACHING OF GREENHOUSE EFFECT IN CHEMISTRY LABORATORY
}

\section{BEATRICE ARISA AROP AND FELICIA IMEH UMANAH}

(Received 25, June 2014; Revision Accepted 1, July 2014)

\begin{abstract}
The teaching of greenhouse effect is difficult and is done in abstraction. This paper suggests a new instrument, called Improvised Greenhouse Effect Apparatus (IGHA) for the teaching of Greenhouse effect. 100 students were randomly selected from the Department of Chemistry, Cross River State College of Education, Akamkpa for the study. The students were exposed to practical classes for 5 days, 2 hours every day. After the end of the practical exercise, the students were allowed to conduct the practical exercise on their own. The result showed that the students' experimental result and the researchers' experimental data are the same. It was concluded that the students understood the concept of greenhouse effect using the improvised apparatus. It was suggested that the apparatus would be adopted in teaching Greenhouse Effects in schools.
\end{abstract}

\section{INTRODUCTION}

Greenhouse Effect is a term used to explain the rise in temperature on earth as certain gasses in the atmosphere trap energy. These gases are majorly water, vapor, carbon (iv) oxide, methane and chlrofluoro carbon. Their effects in the atmosphere has become so devastating and harmful to man and his environment that it has become a global concern. Greenhouse gases result in global warming due to excessive heat. Other effects of greenhouse effects are: cancer, catarrh, lung impairment, bronchitis and draught. However, without this greenhouse heating, the earth's average temperature would be only about $\left(-73^{\circ} \mathrm{C}\right)$ even the oceans would be frozen (Nwalizu, 2008).

Greenhouse effect is not a common concept in Chemistry. Both teachers and students perceive it as an abstract concept (Eshiet, 1998). This is evident from the poor performance of students when questions are set on this concept. The students and teachers perceive the concepts as abstract and difficult to learn and teach (Eshiet, 1998). The delivery of this difficult concept is often done in abstraction. Therefore the researchers have adapted an improvised apparatus that could be used to teach greenhouse effect to chemistry students in secondary as well as tertiary institutions. In this study only carbon (iv) oxide $\left(\mathrm{CO}_{2}\right)$ which is the most prevalent greenhouse gas is studied. This gasis chosen because of its importance to man and animals as well as its constant emission into the atmosphere bythe actions of living organisms. Carbon (iv) oxide has atmospheric concentration (ppm) of 331.3 and an annual of $0.4 \%$. it has a current contribution of $57 \%$ which is higher than all other greenhouse gases (Bhatia in Nwahizu 2012). The introduction of this gas into the atmosphere by the action of man through burning of fossil, fuel, coal, natural gas, deforestation and so on is increasing as a result of agricultural and industrial activities. It becomes necessary

Beatrice Arisa Arop, Department of Integrated Science, Cross River State College of Education, Akamkpa, Cross River State, Nigeria

Felicia Imeh Umanah, Department of Science Education, Akwa Ibom State University, Ikot Akpaden Mkpatenin Local Government Area, Akwa Ibom State, Nigeria 
therefore to carry out a study on how this gas is generated in the laboratory and possible apparatus to construct a miniature Greenhouse in order to teach the generation and effect of carbon iv oxide in the laboratory.

\section{Empirical Studies Of Effect Of Greenhouse Gases And Global Warming.}

Beginning with work by Joseph Fourier in the 1820 s, scientists had understood that gases in the atmosphere might trap the heat received from the sun. As Fourier puts it energy in the form of visible light from the sun easily penetrate the atmosphere to reach the surface and heat it up, but heat cannot so easily escape back into space. For the air absorbs invisible heat rays (infrared radiation) rising from the surface helping it stay warm. This effect was later called Greenhouse effect.

In 1859, Tyndal sets out to find whether they were in fact any gas in the atmosphere that could trap heat rays. He discovered gases like water vapour $\left(\mathrm{H}_{2} \mathrm{O}\right)$ which was the most important and carbon (IV) oxide which was only a few parts in ten thousand. Just as a sheet of paper blocks more light than an entire pool of clear water, so the trace of $\mathrm{CO}_{2}$ altered the balance of heat radiation through the entire atmosphere.

In 1996 Svante Arrhenius suggested that cutting the amount of $\mathrm{CO}_{2}$ in the atmosphere by half could lower the temperature in Europe some $4-5^{\circ} \mathrm{C}$ (roughly $7-9^{\circ} \mathrm{F}$ ), that is, to an ice ages level. In the same year Hogbom calculated the amount of $\mathrm{CO}_{2}$ emitted by factories and other industrial sources and found that human activities were adding $\mathrm{CO}_{2}$ to the atmosphere at a rate roughly comparable to the natural geochemical processes that emitted or absorbed gas.

In 1938 G.S Calendar argued that the level of $\mathrm{CO}_{2}$ was climbing and raising global temperatures.

In 1960s C.D Kelling measured the level of $\mathrm{CO}_{2}$ in the atmosphere and discovered that it was rising fast. Researchers began to take interest struggling to understand how the level of $\mathrm{CO}_{2}$ had change in the past, and how the level was influenced by chemical and biological forces.

In 1993 Rudd reported that substantial increase in $\mathrm{CO}_{2}$ in the air can cause two detrimental effects- $\mathrm{CO}_{2}$ can increase the temperature of the atmosphere and can increase the acidity of the ocean and $\mathrm{CO}_{2}$ increase the temperature by the greenhouse effect. $\mathrm{CO}_{2}$ like the glass of greenhouse let the shorter wavelength of light through but takes in the longer wave lengths as they are emitted from the surface of the earth. The study noted that $\mathrm{CO}_{2}$ emits the absorbed energy as heat radiation, some of which return to the earth, some energy and others molecules.(www.aip.org/history/ climate $/ \mathrm{Co}_{2} \mathrm{com}$ ).

However, Nwahuzu (2007) conducted a study on the laboratory simulation of Greenhouse Effect. In this study a miniature atmosphere was simulated using test tube with various gases in the laboratory. The study used four different gases $\mathrm{CH}_{4}, \mathrm{NO}_{2}, \mathrm{H}_{2} \mathrm{O}$ and $\mathrm{CO}_{2}$. It was found that all these gases contribute at different levels to the global warming of the atmosphere. Each gas was heated to $60^{\circ} \mathrm{C}$ and allows to cool freely under the laboratory conditions. The pattern of the cooling curve when compared to that of control experiments revealed the contributory effects of each gas toward global warming (greenhouse effect) that is heat retention capacity. The result revealed that the order of contribution of the gases to greenhouse effect are $\mathrm{CH}_{4}>>\mathrm{H}_{2} \mathrm{O} \geq \mathrm{N}_{2} \mathrm{O}>\mathrm{CO}_{2}$. The study also revealed that $\mathrm{CO}_{2}$ is generated by the activities of man on the environment and in the laboratory using an improvised glass wares.

\section{Theoretical Framework}

The second law of thermodynamics is consistent with greenhouse effect which is directly observed. The atmospheric greenhouse house effect, an idea that many authors trace back to the traditional works of Fourier 1824, Tyndal 1861, Arhenius 1896 and which is still supported in global climatology, essentially describes a fictitious mechanism, in which a planetary atmosphere acts as a heat pump driven by an environment that is radioactively interacting but radioactively equilibrated to the atmosphere system. According to the second law of thermodynamics such a planetary machine can never exist (Gerlich, 2009)

The second law of thermodynamics as stated by Rudolf Clausius states

"Heat generally cannot flow spontaneously from a material at lower temperature to a material at higher temperature". 
In simple analogy, if you put something hot next to something cold, the hot thing would not get hotter, and the cold thing would not get colder. We can further explain the second law of thermodynamic in relation to greenhouse effect by the use of a blanket that keeps us warm. If the skin feels cold, wrapping yourself in a blanket can make you warmer, because your body is generating heat, and that heat is escaping from your body into the environment. When you wrap yourself in a blanket, the loss of heat is reduced, some is retained at the surface of your body, and you warm up. You get warmer because the heat that your body is generating cannot escape as fast as before. Summarily, Heat from the sun warms the Earth, as heat from your body keeps you warm. The Earth loses heat to space, and your body loses heat to the environment. Greenhouse gases slow down the rate of heat lost from the surface of the Earth, like a blanket that slows down the rate at which your body loses heat. The result is the same in both cases, the surface of the Earth, or of your body, gets warmer supports the second law of thermodynamics (Wildish, 2010).

The Concept of Greenhouse Effect The term Greenhouse effect was first coined by J. Fourier in 1827 . The rise in the earth's temperature due to collection of gases such as carbon (iv) oxide, water, vapor, chlorofluorocarbon, nitrogen monoxide and methane gas in warm air trapped by a mass of cold air. This results in retention of infrared rays from the sun and increased surface temperature with the melting of some polar ice. This is referred to as greenhouse effect (Nwalizu, 2007).

Greenhouse effect has been widely used to describe the trapping of excess heat by the rising concentration of carbon (iv) oxide in the atmosphere. The carbon (iv) oxide strongly absorbs infrared and does not allow much of it to escape into space (www.epa.gov). The atmosphere contains a number of gases that act like the glass in greenhouse. They are transparent to visible light from the sun. and allow it to pass through the earth below but they are absorbed and trapped by infrared (IR) light radiation outward from the earth and convert it to heat. A number of industrial and agricultural activities generate and emit water and other gases in the atmosphere. For instance, burning of fossil fuels (coal, oil and natural gases) emits carbon (iv) oxide $\left(\mathrm{CO}_{2}\right)$ and this act increase the amount as gases in the atmosphere.

\section{Green House Effect}

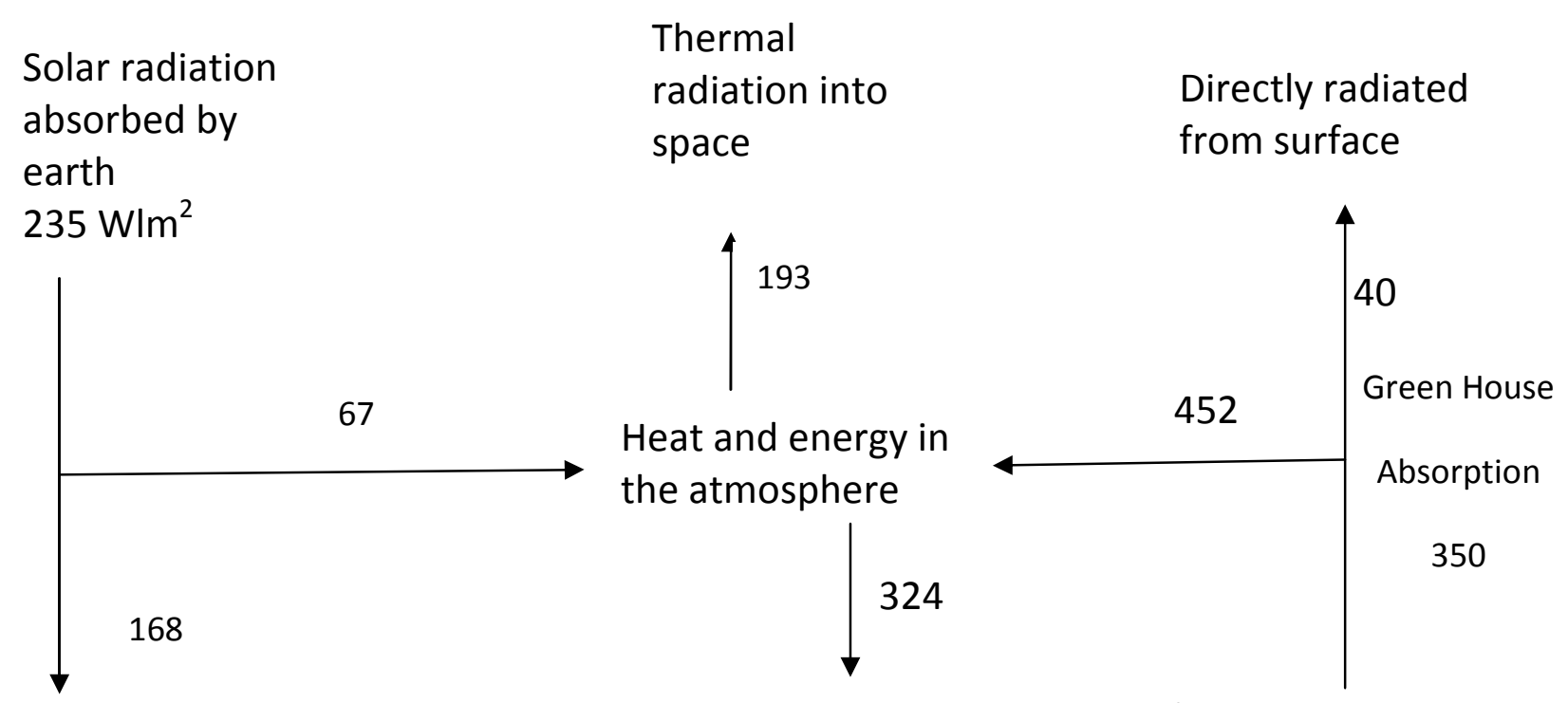

Earth's land and ocean surface warmed to an average of $14^{\circ} \mathrm{C}$

Fig 1: http:/www.cgd.ucar.edu/cas/abstracts/files/kevin1997/htm/. 
This figure is a simplified schematic representation of the flow of energy between space, the atmosphere, and the earth's surface and shows how these flows combine to trap heat near the surface and create the greenhouse effect. This process by which energy is recycled in the atmosphere to warm the earth's surface is known as the greenhouse effect and is an essential piece of Earth's climate (en.wikipedia.org/greenhouse effect).

The earth is getting heat-trapping gases to the atmosphere, mainly by burning fossil fuels. These gases are called greenhouse gases. The principal greenhouse gases are carbon (iv) oxide $\left(\mathrm{CO}_{2}\right)$, nitrous oxide $\left(\mathrm{N}_{2} \mathrm{O}\right)$, methane $\left(\mathrm{CH}_{4}\right)$, Chlorofluorous Carbons (CFCs) and water vapor $\left(\mathrm{H}_{2} \mathrm{O}\right)$.Warmer temperatures are causing other changes around the world, such as melting glaciers and stronger storms. These changes are happening because the earth's air, water and land are all linked to the climate. The earth's climate has changed before, but this time is different. People are causing this changes, which are bigger and happening faster than any climate changes that modern society has ever seen before (www.epa.gov).

The greenhouse effect is a process by which thermal radiation from a planetary surface is absorbed by atmospheric greenhouse gases, and this re-radiation is back towards the surface and lower atmosphere, it results in an elevation of the average surface temperature about what would be in the absence of the gasses (IPCC, 2010, Claussen, Cochran and Davis, 2001).Solar radiation at the frequencies of visible light largely passes through the atmosphere to warm the planetary surface which then emits this energy at the lower frequencies of infrared thermal radiation. Infrared radiation is absorbed by greenhouse gases, which in turn re-radiate much of the energy to the surface and lower atmosphere. The mechanism is named after the effect of solar radiation passing through the glass and warming a greenhouse, but the way it retains heat is fundamentally different as a greenhouse works by reducing airflow, isolating the warm air inside the structure so that heat is not lost by conversion (Schroeder, 2000, Claussen et al, 2001).

Earth natural greenhouse effect makes life as we know possible. However, human activities primarily the burning of fossil fuels and clearing of forest have intensified the natural greenhouse effect, causing global warming (Solomon et al, 2007).

The action of carbon (iv) oxide and other greenhouse gases in trapping infrared radiation is called greenhouse effect. And this in a way would measurably increase the overall average temperature of the earth which could have disastrous consequences (hyperphysics).

\section{Approximate effect of greenhouse gases}



Analyst data from Kraustair and Ristimes,. Energy and Problems of a Technical Society

Fig. 2 cited 1990. Hyper physics.phy.astr.gsu.edu 


\section{Relative warming contributions of different greenhouse gases}

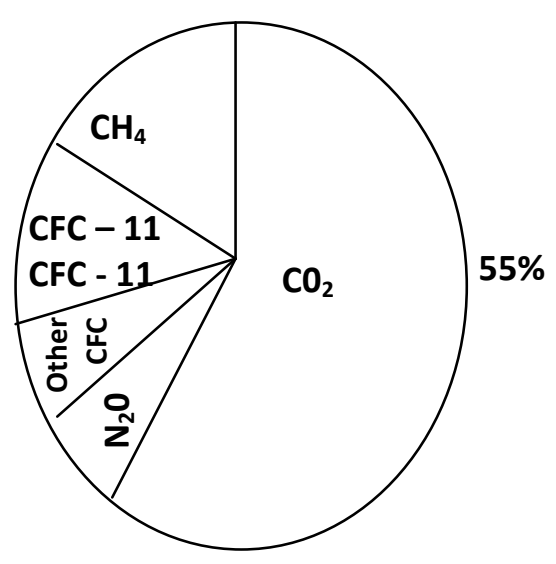

Updated April 17, 2002p. Demenocal (Loco, Columbia University).

$\mathrm{CO}_{2}$ has the highest concentration at $360 \mathrm{pmm}$. $\mathrm{CH}_{4}$ is much less at $1.65 \mathrm{ppm}$ but it is 20 to 30 times as effective as an infrared absorber.

Chlorofluorocarbons have a concentration of only about $10-20$ ppt but they are some 10,000 times as effective at absorbing infrared. Current analysis suggests that the combustion of fossil fuel is a major contributor to the increase in the $\mathrm{CO}_{2}$ concentration, such contribution being 2 to 5 times the effect of deforestation (hyperphysics).

\section{Sources and Effect of Carbon iv oxide in the atmosphere}

Carbon (iv) oxide is a gas generated artificially from agricultural and industrial activities e.g burning of fossil emit $\mathrm{CO}_{2}$, a number of factories spread all over the world burn immense quantity of coal, oil and natural gases and release huge amount of $\mathrm{CO}_{2}$. A large fleet of automobiles, railways and aircrafts, and so on use an immense quantity of diesel and petrol thereby releasing huge amount of $\mathrm{CO}_{2}$ into the atmosphere every year. Also burning of fire woods and deforestation are major sources for the production of $\mathrm{CO}_{2}$ and from chemical reactions e.g in cement production.
Naturally $\mathrm{CO}_{2}$ comes from respiration of animals, plants and humanity, decaying of biomass, natural forest fires, ocean emissions and so on. In the laboratory, $\mathrm{CO}_{2}$ can be generated by reacting, dilute hydrogen chloride or tetraoxosulphate (iv) acid with a carbonate salt.

$\mathrm{CaCO}_{3}+2 \mathrm{HCl} \longrightarrow \mathrm{CaCl}_{2}+\mathrm{CO}_{2}+\mathrm{H}_{2} \mathrm{O}$

The $\mathrm{CO}_{2}$ produced by all these actions can cause two detrimental effects - (1) $\mathrm{CO}_{2}$ can increase the temperature of the atmosphere of the oceans, thus result in greenhouse effect. (2) $\mathrm{CO}_{2}$ also results in enormous increase in rainfall and flooding. $\mathrm{CO}_{2}$ released in the atmosphere can last in the environment for about a century if not sufficiently used by plants and this could lead to the possible cause of global warming.

This study is poised to investigate the generation of carbon (iv) oxide in the laboratory using an improvised greenhouse effect apparatus. This is intended to simplify the teaching of abstract concept in chemistry curriculum.

\section{Research Questions}

The following research questions guided the study:

1. To what extent do teachers use improvised materials in the teaching of greenhouse effect? 
2. What is the performance of students when taught greenhouse effect using improvised apparatus?

\section{Method}

The study is purely experimental. 100 students were randomly sampled from the Department of Chemistry in the Cross River State College of Education, Akamkpa. The students were taught the topic Greenhouse Effect using an experimental set up representing a miniature greenhouse. The study lasted for two weeks and 2 hours intensive teaching every day for ten days making a total of 20 hours.
The innovated apparatus was made up of locally acquired glass wares and materials. The materials included rubber tubes, round bottom flask, conical flasks, boiling tube, funnel, tripod stand, clamp stand, thermometer, measuring cylinder, adjustable chips and water bath. These were properly washed in liquid detergent, rinsed and dried before used. Calcium trioxocarbonate (iv) was used to generate carbon (iv) oxide, $\left(\mathrm{CO}_{2}\right)$ in hydrogen chloride or trioxonitrate (iv) acid. Diagram of experimental set up or innovated apparatus is shown below:

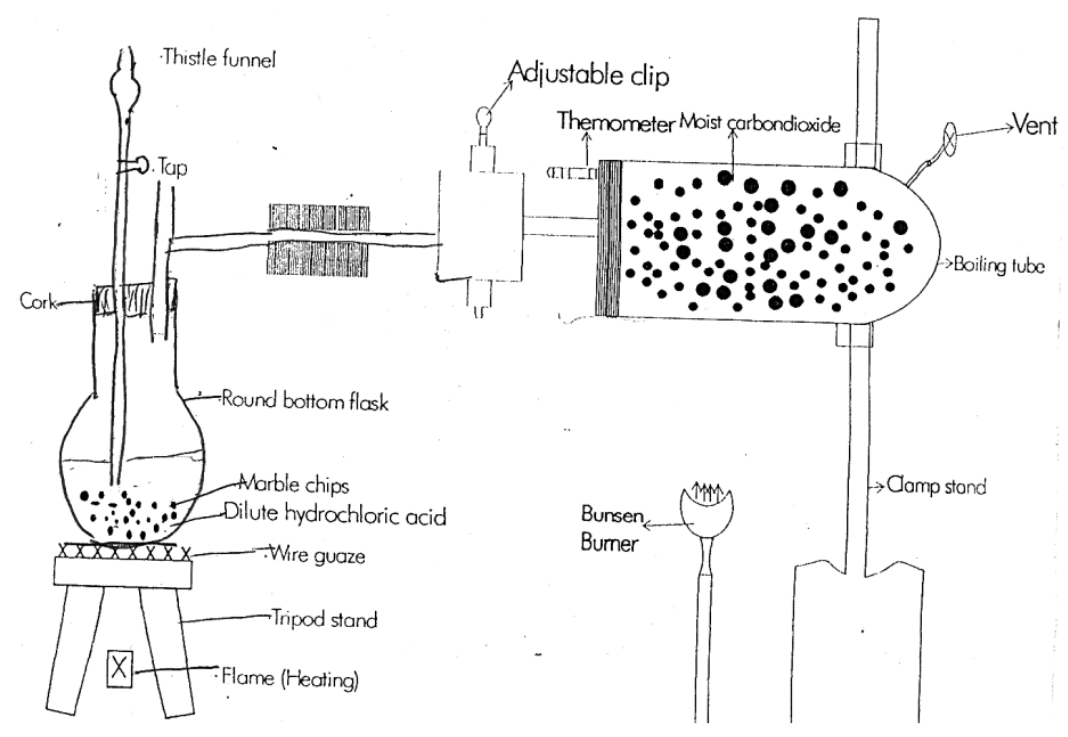

Fig 3: GENERATION OF EXPERIMENTAL CARBON(IV)OXIDE $\left(\mathrm{CO}_{2}\right)$ An Improvised greenhouse (IGH) Adopted from Nwachizu 2007

\section{Laboratory Procedure For Teachers And Students}

Put calcium trioxocarbonate (iv) salt (marble chip) in a flat bottom flask. Add dilute hydrogen chloride or trioxonitrate (iv) acid to the chip. The gas that is formed is collected over water, because Carbon (iv) oxide is slightly soluble in water. If the gas is needed dry, it is passed through potassium hydrogen trioxocarbonate (iv) solution to remove any acid fumes and then through a u-tube containing fused calcium chloride to eliminate water vapor. The dry gas is collected by downward delivery as $\mathrm{CO}_{2}$ is denser or heavier than air.

$\mathrm{CaCO}_{3}(\mathrm{~g})+2 \mathrm{HCL}(\mathrm{aq}) \quad \mathrm{EaEl}_{2}(\mathrm{aq})+\mathrm{H}_{2} \mathrm{O}+\mathrm{CO}_{2}$ (g)

$\mathrm{NaHCO}_{3}(\mathrm{aq})+\mathrm{HNO}_{3}(\mathrm{aq}) \quad \mathrm{NaNO}_{3}+\mathrm{H}_{2} \mathrm{O}+\mathrm{CO}_{2}$ (g)

$\mathrm{CO}_{2}$ can also be gotten by heating metallic trioxocarbonate (iv) salt apart from those of sodium and potassium or the hydrogen trioxocarbonate (iv) of sodium or potassium. 
Carbon (iv) oxide is colourless, odourless gas with a refreshing taste.

\section{Control Experiment}

The control experiment was carried out with empty vessels to ascertain the heat retention of the gas. The temperature rise to $60^{\circ} \mathrm{C}$, the same with that of component gas. The control is accurately measured and recorded with the same time comparing to the sample experiment.

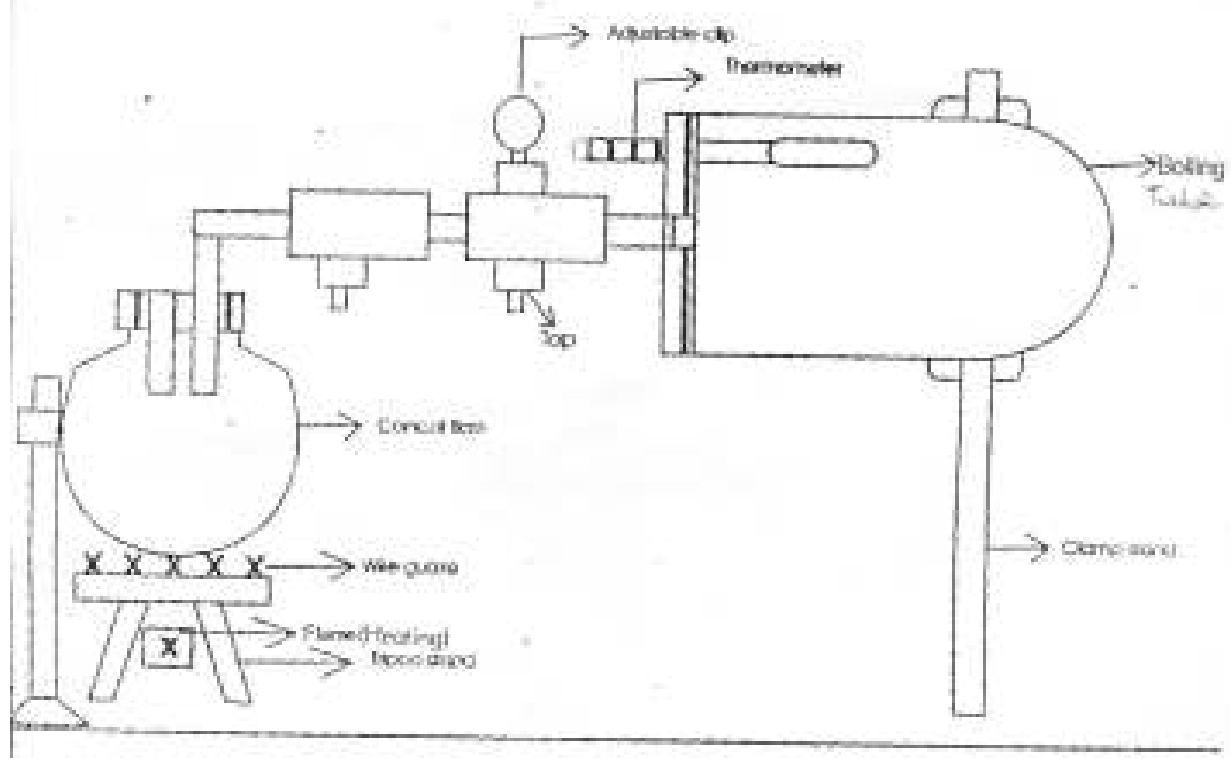

Fig 4: A MINIATURE GREENHOUSE

Adopted from Nwachizu 2007

\section{RESULT}

The result of the practical work is indicated as follows:

Table I: Effect of $\mathrm{CO}_{2}$ Researchers' (Teacher's) Result

\begin{tabular}{|l|l|l|l|l|}
\hline Time/Min & Experimental ${ }^{\mathbf{0}} \mathbf{C}$ & Control ${ }^{\mathbf{0}} \mathbf{C}$ & $\mathbf{T}_{\mathbf{i}}-\mathbf{T}_{\mathbf{f}}$ & $\mathbf{T}_{\text {ex }}-\mathbf{T}_{\text {cort }}$ \\
& & & & \\
\hline 0 & 60.00 & 60.00 & 0.00 & 0.00 \\
\hline 1 & 58.00 & 57.0 & 1.50 & 1.50 \\
\hline 2 & 56.00 & 53.50 & 4.00 & 2.50 \\
\hline 3 & 45.00 & 50.00 & 5.50 & 4.50 \\
\hline 5 & 52.00 & 49.60 & 8.00 & 2.40 \\
\hline 6 & 50.00 & 48.60 & 10.00 & 1.40 \\
\hline 7 & 48.00 & 48.60 & 11.50 & 0.50 \\
\hline 8 & 48.50 & 47.00 & 11.50 & 1.50 \\
\hline
\end{tabular}

$\mathbf{T}_{\mathbf{i}}$ - Initial Temperature, $\mathbf{T}_{\mathbf{f}}$ - Final Temperature, Tex -Experimental Temperature, $\mathbf{T}_{\text {cont }}-$ Control Temperature 
Table 2: Students' Experimental Result

\begin{tabular}{|l|l|l|l|l|}
\hline Time/Min & Experimental 0 & Control $\mathbf{0}^{C}$ & $\mathbf{T}_{\mathbf{i}}-\mathbf{T}_{\mathbf{f}}$ & $\mathbf{T}_{\text {ex }}-\mathbf{T}_{\text {cort }}$ \\
& & & & \\
\hline 0 & 60.00 & 60.00 & 0.00 & 0.00 \\
\hline 1 & 58.00 & 57.0 & 1.50 & 1.50 \\
\hline 3 & 56.00 & 53.50 & 4.00 & 2.50 \\
\hline 4 & 45.00 & 50.00 & 5.50 & 4.50 \\
\hline 5 & 52.00 & 49.60 & 8.00 & 2.40 \\
\hline 6 & 50.00 & 48.60 & 10.00 & 1.40 \\
\hline 7 & 48.00 & 48.60 & 11.50 & 0.50 \\
\hline 8 & 48.50 & 47.00 & 11.50 & 1.50 \\
\hline
\end{tabular}

$\mathbf{T}_{\mathbf{i}}$ - Initial Temperature, $\mathbf{T}_{\mathbf{f}}$ - Final Temperature, Tex -Experimental Temperature, $\mathbf{T}_{\text {cont }}-$ Control Temperature

Table 3: Comparing Researchers'/Teachers' Results with Students' Result

\begin{tabular}{|c|c|c|c|c|}
\hline Time/Min & $\begin{array}{l}\text { Heat Absorption } \\
\text { In Temp. Range } 0^{c}\end{array}$ & 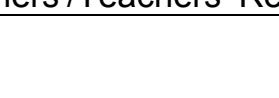 & Maximum Temperat & re Change $0^{c}$ \\
\hline $\mathrm{CO}_{2}$ & Researchers' Result & Students' Result & Researchers' Result & $\begin{array}{l}\text { Students' } \\
\text { Result }\end{array}$ \\
\hline & $0.20-4.50$ & $0.20-4.50$ & 4.50 & 4.50 \\
\hline
\end{tabular}

\section{DISCUSSION}

The researchers results show heat absorption to have a temperature range of $0.20-$ 4.50. The maximum temperature change for researchers experiment is 4.50 , while that of students is also 4.500. This shows that the students results are the same with that of the researchers thus, the students understood the experiment using the improvised apparatus. The results also show that carbon (iv) oxide emits temperature of $4.50^{\circ} \mathrm{C}$ into the atmosphere. This temperature is sufficient to result in excess heat and greenhouse effect. This result agrees with the reports of hyper physics and that of Nwahizu (2007).

However, the study also shows that teachers effectively teach greenhouse effect to students by the use of the improvised apparatus. This is seen by the performance of the students in the practical classes. The result of the students being the same with those of the teachers/researchers. Thus if students are adequately motivated, the desired outcome would be obtained.

\section{CONCLUSION}

Greenhouse effect can also be taught using apparatus for the understanding of students as well as increase performance. Chemistry concepts can be taught in concrete terms using improvised apparatus.

\section{RECOMMENDATIONS}

1. Chemistry concepts should be taught using improvised apparatus.

2. Students should be properly taught.

3. Inquiry method should be adopted in teaching chemistry.

4. Hands-on and minds-on inquiry method should be adopted in chemistry classrooms.

5. Greenhouse effect should be taught using the improvised apparatus in this study. 


\section{REFERENCES}

Allaby, A and Allaby, M., 1999. A Dictionary of Earth Sciences, Oxford University Press, ISBN.0-19-2 80079-5 p.244.

Atmosphereic Carbondioxide - 'Mauna Laoa' NOAA

Claussen, E., Cochran U. A and Davis, D. P., 2001. Climate Change. Science Strategies and Solution, University of Michigan p. 373.

Eshiet, I. T., 1996. Improvisation in Science Teaching. Philosophy and practice. Abak: Belpot, Nig.Co.

Gerlich, G., 2009. The greenhouse effect and the $2^{\text {nd }}$ law of thermodynamics. Retrieved on $22^{\text {nd }} \quad$ June. 2014 from www.skepticalscience.com/second law of thermodynamics

hhtp://news.national geographic.com/news/energy/2013/05/13 0510.earth $-\mathrm{CO}_{2}$ milestone -400 . Ppm

Http:/www.cgd.ucar.edu/cas/abstracts/files/Kevin 1997.htm/

Hyperphysics. Phy-astr.gsu.ed/hbase. The Greenhouse effect. Retrieved $18^{\text {th }}$ March, 2014.

Nwahizu, O. N., 2007. Laboratory Simulation of Greenhouse Effect. Unpublished B.Sc Thesis Department of Chemistry, University of Uyo Akwa Ibom.
Solomon S., Qin, D., manning, M., Chen, Z., Marquis, M., Averyt, K. B., Tignor, $M$ and Miller, H. L. ed 2007. Climate Change. The Physical Barisfrouth Assessment Report of the IPCC. Cambridge University Press, ISBN 979-0-521-8009-1 (Pb.978-0-521-705967).

Sources and impacts of Greenhouse V1003 science \& society houses syllabus. Lectures project references eesc.columbia.edu/../edu/greenhousegas/

The Greenhouse effect-national Geographic Retrieved on $18^{\text {th }}$ March, 2011 from en.wikipedia.org//greenhouse Effect

www.globalissues.org. Climate Change and global warming updated. $19^{\text {th }}$ January, 2014.

www.skepticalscience.com/second-law thermodynamics updated on $22^{\text {nd }}$ Oct. 2010 by Tonywildish 